\title{
Mastering Internal Growth and Transformation after Miscarriage experience: A Qualitative Study
}

\section{Gisoo Shin}

Chung-Ang University

Hye Jin Kim

Kyungsung University

Sung Hae Kim ( $\nabla$ franciscoasclara@gmail.com )

Tongmyong University https://orcid.org/0000-0001-8252-1317

\section{Research article}

Keywords: women, miscarriage, loss, internal growth, grounded theory

Posted Date: October 9th, 2020

DOI: https://doi.org/10.21203/rs.3.rs-57405/v1

License: (1) This work is licensed under a Creative Commons Attribution 4.0 International License. Read Full License 


\section{Abstract}

Background: The loss is common among many people, but not everyone goes through all of the stages or experiences. Miscarriage is a unique loss experience among the women. The loss and grief experienced after a miscarriage may bring both losses and gains in life. The purpose of this research was to identify the experiences of South Korean women after miscarriage.

Methods: This was a qualitative study based on the Strauss and Corbin methods. A total of 23 participants who had all experienced more than three miscarriages participated in this study. The data were collected through in-depth interviews conducted from May to July 2017.

Results: We found that 47 sub-categories, and 15 categories through the open coding process. Six properties of mastering internal growth and transformation following a miscarriage were identified. "The experience internal growth and transformation through the loss and mother fetal attachment" was proposed as core category.

Conclusions: The findings of this study were meaningful in that they revealed the process of women experiencing internal growth and transformation after miscarriage, breaking away from focusing on negative feelings related to miscarriage. We presented a different angle of experiencing internal growth and transformation with a new perspective on life. The findings indicated the valuable support in the enhanced recovery education and might help them understand the changes in their lives after miscarriage, away from the traditional view of women who have experienced miscarriage.

\section{Background}

There are a variety of ways in which we may experience losing someone in our lives. Loss is defined as a real or potential situation in which a person cannot approach or be approached by an object, they consider valuable, or in which a person has sufficiently changed so that they are no longer able to achieve a worthwhile objective [1]. However, in the death of parents and siblings from sudden accidents, the death of a spouse, and suicide, we experience the sudden loss of our loved ones.

Miscarriage is a unique loss experience experienced by women. Pregnancy and childbirth are important life cycle events for women, during which they experience a very strong sense of well-being that is unlike any feeling that they have experienced before [2]. However, some women experience an unexpected miscarriage, whereby a woman suffers a colossal loss for which she is not yet prepared $[3,4]$. Miscarriage is the termination of life within the 20th week of gestation, at which point a fetus does not have the ability to survive outside of the mother's body [5]. Miscarriage occurs primarily in the early stages of chromosomal anomalies, but it can also occur due to various unknown maternal and environmental factors. One of the characteristics of miscarriage is that it is likely to repeat [6].

In general, those who experience loss suffer negative emotions, such as grief, anxiety, sadness, loneliness, fear, despair, and chaos $[3,7,8]$ In particular, women who miscarry often experience feelings of 
guilt in addition to post-traumatic stress disorder (PTSD) from loss [3,8]. Occasionally, they resent their family or question their Gods, desperate for answers as to why they have experienced a miscarriage.

Miscarriage is a powerful and traumatic loss experienced by women in their life cycle. The Diagnostic and Statistical Manual of Mental Disorders 5 (DSM-V) defines the death of close family as a traumatic event [9]. Psychological trauma from loss may cause negative emotions such as pain or sadness, but may also promote potential growth at the individual level through seeking psychological and physical stability, and developing resilience $[10,11]$. Therefore, women have the opportunity to reflect on their miscarriage experiences and grow through overcoming sadness and difficulties [12]. The traumatic event of loss can lead to posttraumatic growth (PTG), and a positive psychological change that leads to a different life than before [13]. The loss is common among many people, but not everyone goes through all of the stages or experiences in the prescribed order [14].

\section{Methods}

\section{Qualitative approach and research design}

The purpose of this research was to identify the experiences of South Korean women after miscarriage. The grounded theory approach is a qualitative study that helps to develop a theory through the analysis of data belonging to a phenomenon through a series of systematic processes [15]. We identified the stages of loss experienced by women who have suffered a miscarriage using the grounded theory approach based on Standards for Reporting Qualitative Research [16].

\section{Ethical considerations}

This study approved by Institutional Review Board of XXX University (1041078-207105-HRSB-097-01). The purpose and methods of the study were explained to participants before the interview was conducted. The interviews were recorded and transcribed anonymously. Those who volunteered to participate in this study gave written consent. They were also allowed to withdraw from the research at any time.

\section{Data collection and analysis}

The data collection was collected by this research team consisting of professors (GS) and doctoral students ( $\mathrm{HJ}$ and $\mathrm{SH})$. First author (GS) has a lot of experience in carrying out qualitative research, and co-authors ( $\mathrm{HJ}$ and $\mathrm{SH}$ ) have experience in conducted individual and focus groups interviews, and performed contents analysis using qualitative data. The research team participated in quality research workshops and academic conferences, and was trained in qualitative research methodologies. Through the recruitment announcement (e.g. telephone, online homepage and cafe board) of in this study, participants were recruited for convenience sampling with snowball sampling. The participants were 23 
women who experienced miscarriage in South Korea. There were no reported dropped out. The data were collected through in-depth interviews conducted from May to July 2017. The interview was conducted once. The range of interview time were 40-120 minutes, the average interview time was 90 minutes per person. We conducted the interview using semi-structured questions and probing techniques at hospital or seminar room. The interview guide developed for this study is provided as Additional file 1. We were used audio-tape recorder. During the interview, we wrote a filed note and a transcription note after individual post-interview. When the interviews were complete, we analyzed the source data using the grounded theory method [15]. In the open coding stage, we generated codes by comparing the characteristics of data with meaningful words and sentences, and constructed categories of concepts using the NVivo 10.0 program. In the axial coding stage, we identified the organic connection between categories and subcategories around the axis of categories. The core categories were then derived and refined through theoretical coding in order to integrate all categories.

\section{Trustworthiness}

To maintain high standards for the study, research quality was managed by taking the concepts of factual value, applicability, consistency, and neutrality into consideration, as presented in the work of Guba and Lincoln [17]. In addition, the data were interpreted and verified several times using field notes and transcription notes [18]. As for the analysis of the study results, we derived meanings through crosschecking the coding contents between researchers several times, and obtained credibility through the evaluation of three experts and a consultation process [19].

\section{Results}

\section{Characteristics of participants}

The age range of participants was 28 to 42 years. The mean frequency of miscarriage of participants was 3.87 times, ranging from three to 10 times per participant (Table 1). In the final result of open coding, 107 concepts were grouped together with similar concepts, resulting in 47 subcategories. In the stage of selective coding, 15 categories identified. The relationship between loss and mother-fetal attachment is proposed as a core category with six properties of mastering internal growth and transformation following a miscarriage (Fig. 1).

Table 1

General characteristics of participant $(n=23)$

\begin{tabular}{|lll|}
\hline & Range & Average \\
\hline Age & $28-43$ years & $36.3 \pm 3.75$ \\
\hline Level of education & College or university & \\
\hline Number of miscarriages & $3-10$ & $3.87 \pm 1.68$ \\
\hline
\end{tabular}




\section{Causal conditions}

The causal condition of this study turned out to be a loss. The subcategories of loss were predicted miscarriage, spontaneous abortion. All participants experienced a very painful time due to loss.

I was married at the age of 39 . The doctor recommended hospitalization at seven weeks of pregnancy, but I could not afford to be hospitalized... I went to the hospital a week later and my baby's heart was not running. I could not believe it and I was shocked (P 4, 40s).

\section{Context}

The categories of contextual conditions herein were maternal instincts, conflict of self-actualization, and avoidance of pregnancy-related topics.

I went to the province from Seoul [great city] to find a doctor who was famous for trying to save my baby somehow, but I was told that the time to save the baby was too late... My husband's family wanted a child too, and I also didn't want to be stressed anymore. (P 16, 40s).

\section{Phenomenon}

The phenomenon is the primary experience of participants. The mother-fetal attachment was found to be the reoccurring phenomenon.

Basically, the child is to be buried in the chest. No matter how it was in the belly, the child is a child. Pregnancy tester and ultrasound pictures are still kept with me. (P 9, 30s)

The child I left is a child I should carry on forever. No matter how healthy the present children are now, I think of the one leaving me once and for all. I still remember. (P 23, 30s)

\section{Intervening conditions}

The intervening conditions in this study were reported spousal empathy, spirituality, and self-help support groups.

I saw my groom cry when I had an abortion. Oh, it's not hard and painful only for me, but it's hard for my husband too... (P 20, 30s)

There were a lot of cases like me when I saw an online social networking. I got information on how pregnant mothers have succeeded in pregnancy (P 18,30s) 


\section{Action and Interaction strategies}

Prayer for the lost fetus, the culture's inherent shamanism, resilience formed through the prospect of future possibilities, and changes in lifestyle were revealed to be the action or interaction strategies of participants.

I went to the [Buddhist] temple for a baby who left me and gave a hundred-day prayer. I've been doing this type of ritual of leading the soul to heaven for three years. Even now, every time it is time to pray, I pray and make an offering... (P 1, 30s)

"Now put the photo of the three goddess of birth governing childbirth in the refrigerator." I knew it, I wanted to buy a mother panty that gave birth to three sons in the hope of believing in superstitions. (P 17, 30s)

\section{Consequences}

Through participants' ability to cope and accomplish internal growth and transformation in the phases of loss, the consequences emerged as the ability to look back on the past, to feel gratitude for the things they have, and to find hope in not giving up. In other words, they experienced internal growth and change.

It was economically difficult and I had no good relationship with my husband. My husband got drunk and got home, told that his heart was so aching. And he cried sorry to me. My mom who was there with me also cried... I realized that they [family] are on my side... I already have enough. (P 3, 40s)

\section{Process of analysis}

We examined the meaning of the miscarriage experience for participants, as well as the processes that led participants to achieve internal growth and transformation following their loss due to miscarriage. Stages of denial, anger, depression, bargaining, acceptance, and accomplishing internal growth and transformation were revealed in this study.

\section{Denial}

Participants who had the joy of realizing pregnancy and expecting a baby tended to experience a stage of unbelievable denial upon experiencing a miscarriage. Participants reported undergoing other examinations by different means, or visiting other hospitals.

I do think... Pregnancy test is wrong...why am I? I still have a hyperemesis... (P 23, 30s)

\section{Anger}


Participants had greater feelings of anger as their expectations for a healthy baby increased with the pregnancy progression. Participants also experienced greater anger with repeated experiences of miscarriage.

Others easily have a good baby and even a baby that they do not want. I wonder why this is happening only to me who strongly craves a child, and I am so angry. (P 22, 30s)

\section{Depression}

As time progressed, participants reported that their degree of depression worsened. Most of the participants were feeling defeated or guilty in isolation. This heightened the feelings of depression.

I cried a lot and I thought that I was wrong and that it was my fault. I had a lot of self-defeats... I also got depression medication. (P 14, 40s)

I felt guilty. I got sorry that I got depressed whenever looking at women who were full-term pregnancy... (P 19,30 s)

\section{Bargaining}

Participants who experienced miscarriage were willing to bargain using habits or jobs that they had done in the past. However, the fear of miscarriage still remained.

After a third miscarriage, I was afraid that I would be miscarried again, so I was laid in my house quit my job. I decided to lie down on the bed for six months. Now, I went to the mother's classroom six months later and listened to my baby's heartbeat, but I was still very afraid. (P 13,30s)

\section{Acceptance}

Participants reported that, after their experiences of miscarriage, they began to make changes in their attitude to find inner peace from the severe conflicts of mind and negative emotions following the loss. This evolution can be described as acceptance.

I thought it was my fault, it must be a divine intervention that this happened. I thought I couldn't meet baby because something was not good. (P 15,30s)

\section{Internal growth and transformation}

Participants were able to shift their point of view to a new one that they had not considered in the past. They had a transformative perspective on life. They became grateful, satisfied in their relationships with 
family, and were able to grow and cope better with the present situation.

My age is over 40 now, but I think I got to be just an adult. The point is that I'm growing (P 11, 40s).

The experience of miscarriage is like mud in the water... I don't think it can be cured. But I think the experience of spontaneous abortion is meaningful. I knew the gratitude of my life and came to think about what I would do as a good person. (P 6, 40s)

\section{Discussion}

One of the basic assumptions of positive psychology is that everyone ultimately pursues internal growth [20]. Similar to the theory of posttraumatic growth, which also leads to positive thinking through a traumatic experience, giving rise to a new perspective on life [13]. For this study, we conducted an indepth investigation of the process of achieving internal growth and transformation through women who have experienced loss due to miscarriage.

The participants reported that the maternal-fetal attachment lasted after miscarriage. Attachment is the tendency of an individual to pursue proximity based on strong emotional ties with the person closest to the individual [21]. The participants believe that holding onto the lost fetal connection almost brings a second baby to life. They believed that the loss of the fetal connection to miscarriage brought blessings. The feeling of being blessed is fused with faith, maintained in forms of shamanism, as well as religions such as Confucianism and Buddhism [22]. In Asian nations such as China and Korea, longevity, wealth, value, health, and offspring are considered elements of blessed people. These are not objectively obtained, but rather are more affected by fate or certain factors [23]. Participants in this study also expressed that, at the stage of acceptance in their grief, they felt that miscarriage and pregnancy was heavewill and destiny.

A miscarriage is a trauma in the sense that it is a great loss to a mother and her spouse, and is a shocking traumatic event that disrupts lives. In this study, participants who had experienced miscarriage suffered from negative emotions of anger and depression due to spontaneous abortion. However, they underwent the discrete stages of bargaining and acceptance to achieve the phenomenon of internal growth. PTG is a positive psychological change resulting from an individual's struggle to overcome and cope with an experience of trauma or crisis [13]. It suggests that internal growth comes about by individuals being able to find intrinsic value, appreciation, and a new meaning in life [13,24]. In this study, participants reported negative emotions from miscarriage such as grief, anxiety, fear, guilt, and sadness, which were transformed into resilience and positive thinking. This is in line with previous research that suggests that resilience or experience with traumatic events leads to posttraumatic growth, which is not just a memory of negative emotions, but a new perspective on life [25]. According to the PTG theory [13] reflection on trauma leads to positive changes that take place in a different world, thereby facilitating wisdom and a new perspective on life. Participants of this study reported experiencing changes in cognitive schema with positive attitudes toward life, rising from the desperate crisis of miscarriage. The 
higher the resilience, the quicker one can adapt to environmental changes, become free from traumatic events, find psychological stability, and ultimately experience potential growth $[10,11,26]$.

In this study, the significance of miscarriage, as experienced by the participants, was reflected in Korean society beyond the physiological and physical dimensions of the event. For Korean women, pregnancy and childbirth traditionally represent a link between the past, present, and future. In other words, a baby is a psychological symbol that connects generations, and the baby has the powerful role of guarding the souls of ancestors. In addition, giving birth is one of the essential requirements for practicing filial piety to parents, and one of the most important aspects of well-being for married women $[23,27]$. These notions are based on Confucianism and Buddhist thought, which are rooted in Korean society [28]. Although traditional perceptions of pregnancy and childbirth have changed in the modern era, the occurrence of spontaneous abortion in Korea's family-centered society deepens the liability of the accused, and worsens guilt in the denial and anger stages of the loss cycle, according to the results of this study. Participants in this study experienced resilience, were empowered by religion, and overcame sorrow and difficulty through self-reflection, family, and attending group discussions with women who had the same experience. This study provides an empirical basis to confirm that resilience, as well as family and social support networks are influential factors in posttraumatic growth. Therefore, there is a need to promote resilience and provide social resources, including religious activities, to families, as well as women who have experienced miscarriage.

The experience of loss due to miscarriage is also thought to be meaningful and valuable. The results of this study provide strong evidence that hopeful expectations were not completely terminated in participants who linked the possibility of future childbirth to internal growth through self-reflection and appreciation of their everyday surroundings. For this reason, women suffering from a miscarriage may be able to return to their transformative lives from loss, with resilience and interventional strategies ultimately improving their quality of life by providing emotional support and education. The findings of this study are meaningful in that the medical events of miscarriage were approached as traumatic events based on positive psychology and the PTG theory. Breaking away from focusing on the negative emotions associated with miscarriage, such as guilt, sadness, fear, and depression $[3,8]$, we presented a different angle of experiencing internal growth and transformation with a new perspective on life.

\section{Conclusions}

The findings of this study were meaningful in that they revealed the process of women experiencing internal growth and transformation after miscarriage, breaking away from focusing on negative feelings related to miscarriage. We presented a different angle of experiencing internal growth and transformation with a new perspective on life. Also, we suggest that, although these pregnancies are terminated due to miscarriage, it is still necessary to support the mourning process of letting go of the fetus, to request for new blessings to women and their families, and to develop and apply healing programs to help familylevel recovery. Although the mother loses the fetus during the miscarriage, the fetal-attachment relationship persists beyond time and space. We suggest that sufficient support for the mourning 
process, such as death and bereavement, is needed. Therefore, we also suggest that, although these pregnancies are terminated due to miscarriage, it is still necessary to support the mourning process of letting go of the fetus, to request for new blessings to women and their families, and to develop and apply healing programs to help family-level recovery. Limitations of the study included that the sample was confined to South Korean women. Therefore, it would be beneficial to carry out in-depth comparative research among women in other countries regarding the experience of miscarriage.

\section{Abbreviations}

DSM-V: Diagnostic and Statistical Manual of Mental Disorders 5; PTG: Posttraumatic growth

\section{Declarations}

\section{Ethics approval and consent to participate}

This study approved by Institutional Review Board of Chung-Ang University (1041078-207105-HRSB-09701). The purpose of the study was explained to participants before the interview was conducted. The interviews were recorded and transcribed anonymously. Those who volunteered to participate in this study gave written consent. They were also allowed to withdraw from the research at any time.

\section{Consent for publication}

Not applicable.

\section{Availability of data and material}

The interview questions and COREQ checklist were available online at supplementary materials. The study datasets and materials are available from the $\mathrm{SH}$ who corresponding author on reasonable request.

\section{Competing interests}

The author(s) declared no potential conflicts of interest with respect to the research, authorship, and/or publication of this article.

\section{Funding}

This work was supported by a grant received from the National Research Foundation of Korea (NRF) funded by the Ministry of Science and ICT (No.2017R1A2B4009560). The funding body had no role in 
study design, data collection, analysis, interpretation, manuscript writing, or the decision to submit the manuscript.

\section{Authors' contributions}

$\mathrm{GS}$, and $\mathrm{HJ}$ collected qualitative data regarding in-depth interview. GS, $\mathrm{HJ}$, and $\mathrm{SH}$ analyzed and interpreted the qualitative data. GS, and SH were a major contributor in writing the manuscript. All authors read and approved the final manuscript.

\section{Acknowledgements}

We would like to thank the participants for sharing their experience and giving their time and help to make this study.

\section{References}

1. Rosenblatt PC. Parent grief: Narratives of loss and relationship. New York, NY: Routledge; 2000.

2. Myrskylä M., Margolis R. Happiness: Before and after the kids. Demography. 2014;51(5):1843-66.

3. Robinson GE. Pregnancy loss. Best Pract Res Clin Obstet Gynaecol. 2014;28(1):169-78.

4. Bellhouse C, Temple-Smith MJ, Bilardi JE. "It's just one of those things people don't seem to talk about..." women's experiences of social support following miscarriage: a qualitative study. BMC Womens Health. 2018;18(1):176.

5. Griebel CP, Halvorsen J, Golemon TB, Day AA. Management of spontaneous abortion. Am Fam Physician. 2005;72(7):1243-50.

6. Andersen LB, Dechend R, Karumanchi SA, Nielsen J, Joergensen JS, Jensen TK et al. Early pregnancy angiogenic markers and spontaneous abortion: an Odense Child Cohort study. American Journal of Obstetrics and Gynecology. 2016;215(5):594-e1.

7. Carlson C. Grief and mourning. Behavioral concepts and nursing intervention. Philadelphia: Lippincott Company; 1970.

8. Nakano Y, Akechi T, Furukawa TA, Sugiura-Ogasawara M. Cognitive behavior therapy for psychological distress in patients with recurrent miscarriage. Psychol Res Behav Manag. 2013;6:37.

9. American Psychiatric Association. Diagnostic and statistical manual of mental disorders ( $5^{\text {th }}$ ed.). Arlington, VA: Author; 2013.

10. Bonanno GA. Resilience in the face of potential trauma. Curr Dir Psychol Sci. 2005;14(3):135-8.

11. Bonanno GA, Westphal M, Mancini AD. Resilience to loss and potential trauma. Annu Rev Clin Psychol. 2011;7:511-35.

12. Hwang RH. Relationship between maternal fetal attachment and state anxiety of pregnant women in the preterm labor. Korean Journal of Women Health Nursing. 2013;19(3):142-52. 
13. Tedeschi RG, Calhoun LG. The posttraumatic growth inventory: Measuring the positive legacy of trauma. J Trauma Stress. 1996;9:455-71.

14. Parkes CM, Prigerson HG. Bereavement: Studies of grief in adult life. New York, NY: Routledge; 2013.

15. Strauss AL, Corbin JM. Basics of qualitative research: Techniques and procedures for developing grounded theory (2nd ed.). Thousand Oaks, CA: Sage Publications; 1998.

16. O'Brien BC, Harris IB, Beckman TJ, Reed DA, Cook DA. Standards for reporting qualitative research: a synthesis of recommendations. Academic Medicine. 2014;89(9):1245-51.

17. Guba EG, Lincoln YS. Competing paradigms in qualitative research. In Denzin, Norman K \& Lincoln, Y.S (eds.), Handbook of qualitative research, (163-194), Thousand Oaks, CA: Sage; 1994.

18. Breckenridge J, Jones D. Demystifying theoretical sampling in grounded theory research. Grounded Theory Review. 2009;8(2).

19. Bowen GA. Preparing a qualitative research-based dissertation: Lessons learned. Qual Rep. 2005; 10:208-22.

20. Seligman ME. Positive psychology, positive prevention, and positive therapy. Handbook of Positive Psychology. 2002;2.2002:3-12.

21. Bowlby J. The making and breaking of affectional bonds: I. Aetiology and psychopathology in the light of attachment theory. The British Journal of Psychiatry. 1997;130(3):201-10.

22. Lee JS, Kim MY, Suh EK. Well-being and the Eastern concept of Bok: similarities and distinctions. Korean Journal of Social and Personality Psychology. 2004;18(3):115-25.

23. Kim CY, Kim YH. Reviewing women's rights of self-determination on pregnancy and delivery. Yeungnam Univ. Law Journal. 2017;12(45):107-35.

24. Keyes CL, Shmotkin D, Ryff CD. Optimizing well-being: the empirical encounter of two traditions. J Pers Soc Psychol. 2002;82(6):1007.

25. Ha BY, Jung EJ, Choi SY. Effects of resilience, post-traumatic stress disorder on the quality of life in patients with breast cancer. Korean Journal of Women Health Nursing. 2014;20(1):83-91.

26. Tusaie K, Dyer J. Resilience: A historical review of the construct. Holist Nurs Pract. 2004;18(1):3-10.

27. Gilmore, S. Parental rights and responsibilities. New York, NY: Routledge; 2017.

28. Lim J. Modern Chinese history; Confucius in East Asia: Confucianism's history in China, Korea, Japan, and Viet Nam. Asian Stud Rev. 2016;40(1):137-53.

\section{Figures}




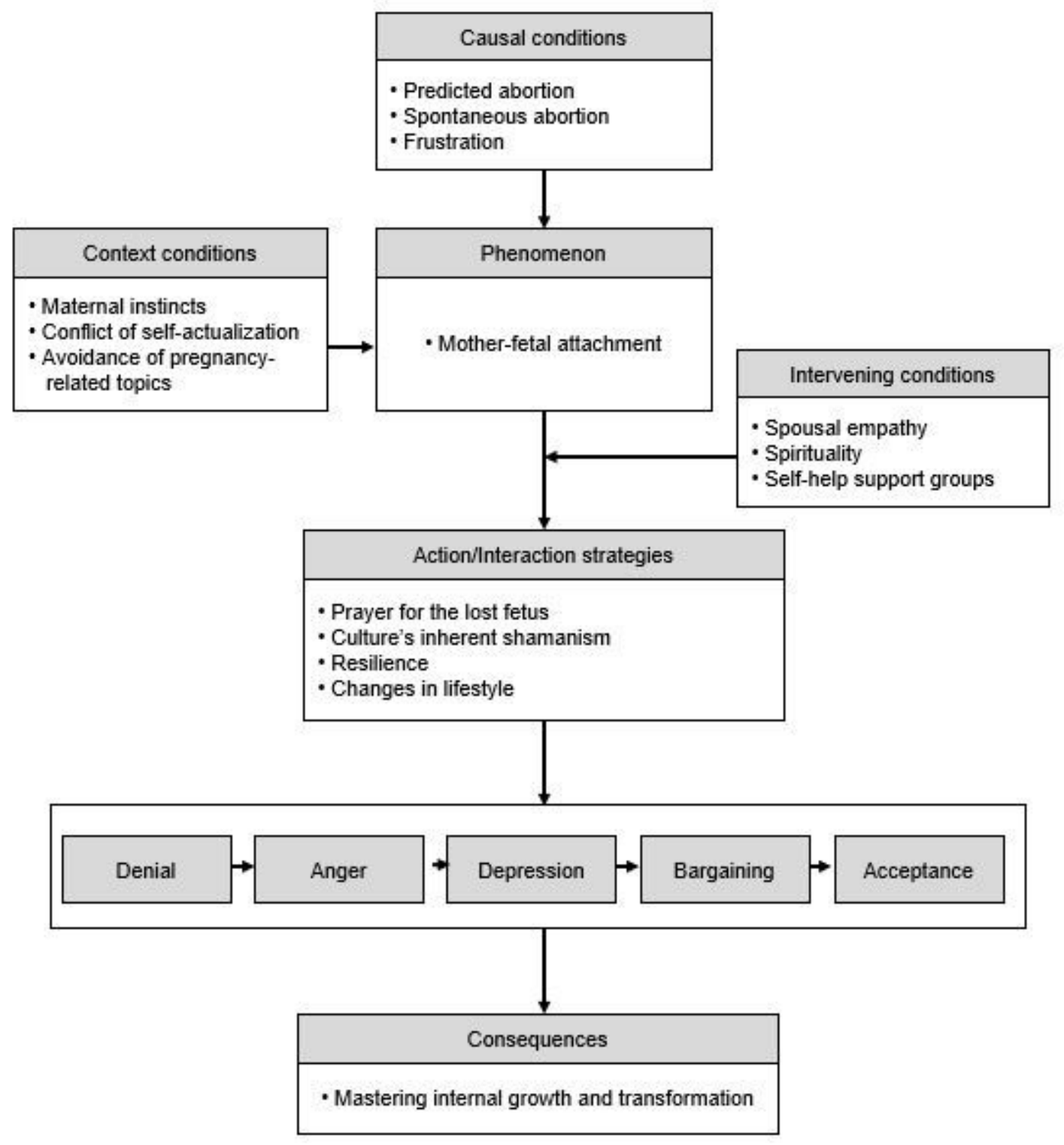

Figure 1

Process of mastering internal growth and transformation for after miscarriage

\section{Supplementary Files}

This is a list of supplementary files associated with this preprint. Click to download.

- AdditionalFile.docx 